\title{
Synchrotron Characterization of Metal Distributions in Soils Collected in the Greater Kamloops Region, British Columbia, Canada.
}

\author{
Connor Arduini ${ }^{1}$, Trevor Flynn², Mark Paetkau ${ }^{1}$, Sharon Brewer ${ }^{1}$, Kingsley Donkor ${ }^{1}$, Kent Watson ${ }^{1}$, \\ Lisa Van Loon ${ }^{2,3}$, and Neil Banerjee ${ }^{2 *}$ \\ 1. Faculty of Science, Thompson Rivers University, Kamloops, Canada. \\ 2. Department of Earth Sciences, Western University, Canada. \\ 3. LISA CAN Analytical Solutions Inc., Saskatoon, Canada. \\ * Corresponding author, neil.banerjee@uwo.ca
}

Kamloops, a city with a population of approximately 100,000 is located in the Thompson Okanagan Region of British Columbia [1]. It is an epicenter of industry with a pulp mill, mines, cement plant, lime plant and water treatment facilities to name just a few. Currently there are two mines located near the city: the New Afton mine operated by New Gold Inc., which is an underground operation situated approximately $10 \mathrm{~km}$ away producing an average of 75 million pounds of copper and 80 thousand ounces of gold annually [2] and the Highland Valley Copper mine operated by Teck Resources Limited, an open pit mine located approximately $50 \mathrm{~km}$ away that has yielded more than 1,100 Mt of ore since its inception [3]. However, it is important to recognize that mining is not the only industrial process emitting airborne particulate matter in the Kamloops area.

Heavy metals are emitted from many different industrial processes including mining, pulp, cement and coal production [4-6]. Therefore, there is potential for heavy metals to be present in dust. Dust particles deposit onto the soil surface, making them susceptible to being absorbed into the soil. In Kamloops specifically, examples of these industries are the Domtar Pulp mill, CP and CN railroad lines, and Lafarge cement plant, all of which may introduce heavy metals into the environment. With all of this industry in the greater Kamloops area that may be contributing heavy metal content to the soils, now is a perfect time to determine a baseline for existing metal content within Kamloops' soils so that future investigations will have a preexisting baseline.

Soil is not deposited homogeneously on the Earth. It develops over time with the influence of living organisms, climate, topography, and parent material separating it into stratified layers known as horizons. They differ from adjacent horizons in properties such as colour, structure, texture and consistency, chemical, biological, and mineral composition. Each horizon is considered separately, as differences in composition, as well as other environmental influences may lead to accumulation or illuviation of toxic heavy metals in a specific horizon [7].

Soils were collected at several locations around Kamloops and divided into the different horizons for analysis. Analysis of select elements by flame atomic absorption spectrometry was previously conducted at TRU [8]. Synchrotron X-ray fluorescence (SR-XRF) analysis offers several advantages for a largescale characterization study: it is rapid, is non-destructive, and the measurement is performed on the soil sample, "as is" - it does not require sample dissolution or digestion. An initial suite of samples was analyzed at both the IDEAS beamline at the CLS (excitation energy 13.5 keV) and at 20-ID at the CLS@APS (excitation energy $26 \mathrm{keV}$ ) for comparison between different excitation energies. SR-XRF MCA spectra were analyzed using the Peakaboo software [9] developed at Western University.

SR-XRF analysis reveals variability in element distribution both vertically through the different soil 
horizons and across the region. Analysis of the parent $\mathrm{C}$-horizon reveals the elemental composition of uncontaminated Kamloops soils, and serves as a baseline composition in this study. Metals in the Ahorizon are likely to include anthropogenic contributions. 2D SR-XRF maps showing variations in Fe, $\mathrm{Cu}$, and $\mathrm{Cr}$ distribution within an A horizon soil sample, along with the average SR-XRF MCA spectrum with $\mathrm{Fe}, \mathrm{Cu}$, and $\mathrm{Cr}$ labeled is shown in Figure 1. Differences in composition between the $\mathrm{C}$, $\mathrm{B}, \mathrm{A}$, and $\mathrm{O}$ horizons may be indicative of deposition and incorporation of dusts emitted from regional industry. The results of this project are now part of a larger PCA analysis to identify industry-specific contributions to the metal content in soils. Further PCA analysis incorporating the SR-XRF results with other environmental and geographical variables will be conducted to develop an in-depth understanding of the mechanisms controlling dust transport, settling, and aging in the greater Kamloops area [10].

\section{References:}

[1] Statistics Canada. 2012. Focus on Geography Series, 2011 Census. Last updated May 29, 2012.

[2] New Gold Inc., http://www.newgold.com/.

[3] Teck Resources Ltd., https://www.teck.com/operations/canada/operations/highland-valley-copper/ .

[4] Department of the Environment. Pulp and Paper Manufacturing Works.

http://publications.environment agency.gov.uk/PDF/SCHO0195BJKZEE.pdf.

[5] Sierra Club. Coal Free Northwest.

http://www.sierraclub.org/coal/wa/downloads/CoalExports_factsheet.pdf .

[6] S. Kakareka and T. Kukharchyk, (2011) "Towards improvement of heavy metals emission assessment methodology from cement production" in EMEP/EEA AEI Guidebook. Belarus: Institute for nature management.

[7] K. Watson, "Soils Illustrated: Field Descriptions", First Ed. Canada: International Remote Sensing Surveys Limited. (2009) p. 2-5.

[8] L. Jmaiff, Investigation of the concentration and distribution of several heavy metals in different soil horizons near Goose Lake in Kamloops, British Columbia, Canada (2014) p. 41.

[9] N. Sherry et al, Science Studio Project Summary. (2012) http://sciencestudio.net/summary.php.

[10] Research described in this paper was performed at the Canadian Light Source (CLS) and Advanced Photon Source (APS). The CLS is supported by CFI, NSERC, the University of Saskatchewan, the Government of Saskatchewan, Western Economic Diversification Canada, the NRC, and CIHR. The APS is an Office of Science User Facility operated for the U.S. Department of Energy (DOE) Office of Science by Argonne National Laboratory, and is supported by the U.S. DOE under Contract No. DEAC02-06CH11357. The authors thank David Muir (IDEAS) and Zou Finfrock (20-ID) for their support in conducting the experiments. The authors acknowledge funding from NSERC.
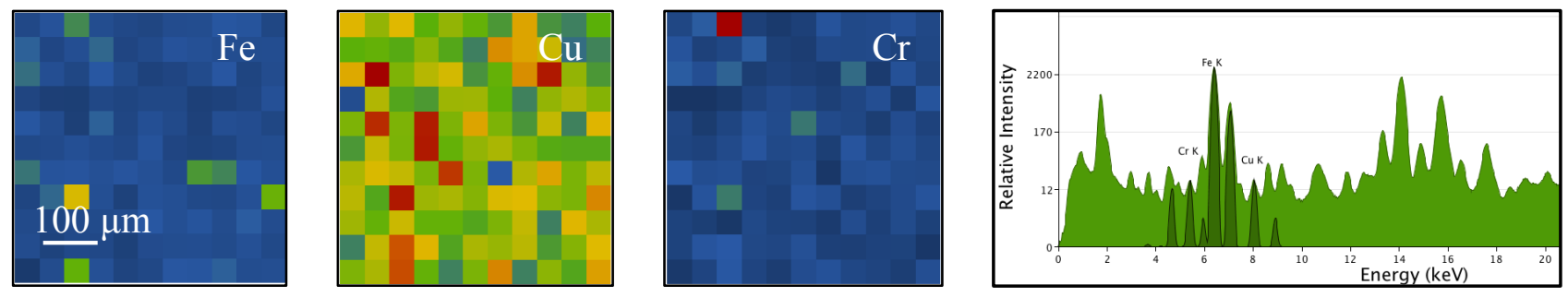

Figure. 1. SR-XRF maps collected with a spot size of $3 \mu \mathrm{m} \times 3 \mu \mathrm{m}$ and a step size of $50 \mu \mathrm{m}$ showing the distribution of $\mathrm{Fe}, \mathrm{Cu}$, and $\mathrm{Cr}$ in an A horizon soil sample along with the average SR-XRF MCA spectrum for the mapped sample. 